Original Research Paper

\title{
Trust as a Mechanism of Social Regulation the Modern Youth's Behaviour
}

\author{
${ }^{1}$ Svetlana Gurieva, ${ }^{1}$ Maria Borisova, ${ }^{1}$ Olga Mikhalyuk, \\ ${ }^{1}$ Victoria Dmitrieva, ${ }^{1}$ Veronika Odintsova and ${ }^{2}$ Takeyasu Kawabata \\ ${ }^{1}$ Saint-Petersburg State University, Saint Petersburg, Russia \\ ${ }^{2}$ Department of Psychology, Shokei Gakuin University, Japan
}

Article history

Received: 08-10-2015

Revised: 22-01-2016

Accepted: 23-01-2016

Corresponding Author: Svetlana Gurieva,

Saint-Petersburg State

University, Saint Petersburg,

Russia

Email: gurievasv@gmail.com

\begin{abstract}
The problem of regulation of social behaviour has been studied of social representations of modern youth. The authors consider that the mechanism of trust can be seen as the basic principle for constructing relations. This article covers issues related to social representations of trust, manifestations of credulity, direction and basic functions of trust. About 380 people have become the subject of the study: 190 men and 190 women aged between 20 and 30 (the average age being 23.78). The study used the following tools: A questionnaire, the authors' modification of Sachs and Levy's Sentence Completion Test and the "Trust Situation" projective technique. The data-processing included content analysis, correlation and factor analysis. The results enabled us to create a classification of people based on differences in perception of the trust phenomenon, trust situations, objects and basic functions of trust. The phenomenon of "trust blindness" has been identified and described for the first time.
\end{abstract}

Keywords: Social Behaviour, Mechanism of Trust, Trust Blindness, Factor Analysis

\section{Introduction}

Trust determines the character and the dynamics of relationships in a society; it ensures and accompanies the process of integration and guarantees stability. Recent years have seen an attempt to use mechanisms of pressure, domination, demonstration of power and authority in order to solve the problem of maintaining social order in modern society, on the socio-economic as well as political level. But pressure and demonstration of power cannot solve the problem of shaping trust-based relationships in the long term. According to Parsons (1998) conceptual approach, trust is a "normatively determined circumstance" of expectation of mutuality in some actions and one of the conditions of maintaining social stability.

For many centuries the problem of understanding has been one of the most popular and relevant issues. It was and remains an object of study for many thinkers, philosophers, politicians etc. For example, The Brockhaus and Efron Encyclopaedic Dictionary provides the following definition: "Trust is a psychic state which makes us rely on an opinion which we consider credible and thus refrain from our own study of the question which could be studied by us" (Zinchenko, 1998).
Although lots of researchers are interested in understanding trust, there is a misunderstanding between the role, synonyms, functions and mechanisms of trust. In early theories that study trust, some authors defined interpersonal trust. Rotter (1967) used a typical statement in one of his scales such as "In dealing with strangers one is better off to be cautious until they have provided evidence that they are trustworthy".

Dasgupta (1988) discussed a person's general willingness to trust others and as a result of his discussion, the author defined trust as a personality trait of people in interaction. In this case, trust is a trait that leads us to the propensity to trust or not to trust (Dasgupta, 1988).

Trust may be connected with the propensity to control our emotions, especially negative emotions. Since regulation of negative emotions, such as anger, evoked in social conflict situations allows individuals to control aggressive responses, it has been regarded as promoting social adjustment. However, clinical psychologists have suggested that suppression of anger sometimes leads to other negative emotions, such as depression and recently it was observed in experimental studies conducted in Japan (Kawabata and Ohbuchi, 2014). Although there are many cross-cultural studies on conflict resolution, few focus on emotion regulation in social conflict. 
To continue the study of this phenomenon, it should be noted that trust is an object of study in many fields: Philosophy (Locke, 1988), sociology (Sztompka, 1999), political studies (Coleman, 2001), economics (Takhanova, 2012). Many foreign researchers study the correlation between economic wellbeing of a society and maintaining trust-based relations. At the same time it is important to note that modern science continues the search for the basic mechanism underlying the disruption of trust-based relations and hence a mechanism of regulating social behaviour. Thus, for example, according to Diamond (2011), most economic problems are caused by the fact that operational expenses of business are too high because of a very low level of trust between people. Trust is the basis of ethical and moral behavioural standards, regardless of the economic indices (Laurens et al., 1990)

As we can see, the importance of studying trust has been cited in various research areas such as economics, philosophy, sociology, psychology, jurisprudence etc. In these areas, we have found not only a great interest to study trust but a challenging task to differ and analyse the definitions. Firstly, there is a misunderstanding between the authors in one area. Secondly, there are differences in describing trust and its factors, phenomena, confidence, values, expectation, social order, dependence etc. Thirdly, there is lack of understanding between trust and confidence, trust and risk behaviour, trust and suspiciousness, trust and dependence. Mayer et al. (1995) have clarified that it is a lack of understanding the differences of both the trusting party and the party to be trusted.

Thus there is no doubt as to the importance of studying the phenomenon of trust for different fields of academia. But its understanding, as well as the understanding of the term itself, is still diverging, although there is a demand for it in the modern society (Table 1).
We can speak about the subject and the object of trust. Antonenko (2006) states that many definitions mention the subject of trust, either explicitly or implicitly-they describe the individual experiencing it and their qualities. Besides, they mention the person at whom trust is directed (it can be a person or a system, a circumstance)-the object of trust. Respective characteristics and qualities of the object, which also serve as the basis for trust, are given. In addition to all of that, trust is opposed to distrust and specific differences, reasons and underlying mechanisms of these phenomena are studied (Antonenko, 2006).

Regarding the issue of dimensions of trust, we can quote P. Sztompka's work which describes three dimensions of trust. On the one hand, trust is seen as a feature of a relationship. Trust consists of bets that each party makes on his or her partner and the given relationship. On the other hand, trust is a personality trait depending on characteristics of personality, its ontogenetic development. Besides, trust depends on cultural context, which determines the norms for the level of trust in given structures and people having a given role. For example there is a cultural norm of trust in university professors and a norm of distrust in people with a criminal record (Sztompka, 1999).

Trust is an object of study in many scientific schools and currents. The socio-psychological aspect of trust was studied by Porshnev (1996) who considered trust and distrust as specific filters, either allowing certain pieces of information through or stopping them. Distrust is a "protective psychic anti-action" and blocks out information that can be harmful. Trust, on the other hand, is "equal to belonging of both participants of the given act to the same 'us', i.e., a pure and complete socio-psychic community not complicated by an intersection with other communities and shaped only by opposition to 'them"'(Porshnev, 1996).

Table 1. Definitions of trust in scientific approaches

\begin{tabular}{|c|c|c|}
\hline Scientific approaches & Authors & Definitions \\
\hline Economic & Romashkin (2011) & $\begin{array}{l}\text { Socio-economical phenomenon of consciousness and a functional } \\
\text { characteristic of social life on the macro, meso and micro levels, seen } \\
\text { as a belief in the reliability of actions and communications with different } \\
\text { actors, and in the predictability of their behavioural reactions. }\end{array}$ \\
\hline Legal studies & Dostovalov (2013) & A factor of shaping legal awareness \\
\hline Philosophy & Stoliar (2008) & $\begin{array}{l}\text { Socio-economic mechanism that guarantees social } \\
\text { development and social order. }\end{array}$ \\
\hline \multirow[t]{3}{*}{ Sociology } & Giddens (1991) & Belief in the reliability of a person and of a social system. \\
\hline & Luhnmann (1988) & $\begin{array}{l}\text { A generalized expectation that the other person will limit his own } \\
\text { liberty in the interest of the system. }\end{array}$ \\
\hline & Seligman (2000) & $\begin{array}{l}\text { A function of activity of social actors realized outside of the sphere of } \\
\text { systemic role expectations. }\end{array}$ \\
\hline Psychology & Gambetta (1998) & $\begin{array}{l}\text { Expectation of favourable behaviour of an object in a situation when } \\
\text { this behaviour is not under control. }\end{array}$ \\
\hline Political science & Dobrokhotov (2010) & $\begin{array}{l}\text { A very important factor of international relations, its role is becoming } \\
\text { more important in the recent years. It is a condition for establishing such } \\
\text { complex international political systems as integration associations. }\end{array}$ \\
\hline Religion & Bible (1990) & A basic and indispensable factor allowing the man to overcome laws of nature. \\
\hline
\end{tabular}


In social psychology trust is the basis for shaping the perception of "us" and "them" in society and is a condition for the emergence and maintenance of a community (Zabolotnaya, 2003). Research on trust and belonging to a circle of important people and others is based on perceptions of "us" and "them". Questions on the overlapping of the circle of trust and the circle of close relations therefore emerge.

Trust fulfils important functions in shaping vertical social relationships. For example, it is included in the mechanism of election of a power authority and provides social basis for the support of government institutions and their political and economic course. The situation of election in itself, according to Zabolotnaya (2003), is an exchange of citizens' social support (credit of trust) against the future decisions of the authority in the interests of the electorate. "In giving credit of trust to certain politicians and denying support to others the voter takes a certain risk. But this risk, in the voter's opinion, is a mean of minimizing the concerns, the uncertainty about the future".

Trust is seen as a condition for credibility (Kapterev et al., 1982). When leaders emerge, members of the group "give them credit of trust, sometimes giving them liberty of action that is unacceptable for them themselves". Trust can have several forms of manifestation: In behaviour, emotional state of a person and attitudes towards the object of trust. Let us consider similar conceptions of social psychologists on behaviour within the framework of the social mind-setting approach.

Alexeeva (2007) proposed an interpretation of trust as a social mindset consisting of three components: Cognitive (what the person thinks about the object and what their ideas of how they should behave with the object are), emotional (what the person feels towards the object) and behavioural (what the person actually does), considering trust in the monetary relations domain. According to the author, trust is characterised by experience of previous interactions between partners. Alexeeva (2007) studied manifestations of trust in situations of institutional loans, where the behavioural component consists of readiness to trust the borrower and emotional and cognitive components reflect the expectations by the potential guarantor (subject of trust) of certain possibilities and intentions of the borrower (object of trust) to fulfil their commitments. In our study we will consider trust mindsets according to this approach.

We can also speak about a common emotional background for shaping trust as a psychological relation. Let us consider the phenomenology of the notion of trust. In Russian psychology the notion of trust was developed owing to research by Kupreychenko (2008). The author described such indispensable conditions for establishing trust as a significant situation, optimistic expectations, the dependence of the subject on the object of trust and, at the same time, voluntary involvement in the interaction and absence of control (Kupreychenko, 2008). Kupreychenko (2008) saw trust as a psychological relation with cognitive, emotional and behavioural components in its structure. The emotional component includes emotional evaluation of the process of trust-based interaction, general emotional background and emotions towards the object and the situation. The cognitive component consists of representations of the object and the situation, an evaluation of the experience of such interaction and expectations concerning the result of the interaction. The conative component is manifested in the readiness to perceive the information given by the partner as true, in the capacity to share responsibility and a degree of self-revealing. According to Kupreychenko (2008), trust and distrust towards given individuals, groups, systems of values, spheres of life, norms and ideas can be evaluated not only by the present state of relationships with these objects but also by the orientation of the subject towards the deepening or destruction of these connections, towards getting closer or estrangement. Trust includes respect and interest towards the object; a notion of the needs that can be satisfied with one's help; emotions connected with their future fulfilment, relaxation, readiness to perform certain actions for successful interaction. Distrust includes understanding of risk, a sentiment of fear and negative emotional evaluations of the object, tension and readiness to cease contact, to show reactive or preemptive aggression. In other words, the mechanism of trust minimizes fear and the threat of "loss of personal meaning" (Kupreychenko, 2008).

The correlation of these two phenomena was studied by Jones (1996) who understood trust as an emotional mindset, an optimistic attitude to the object, to their "good will" and their capacity of doing good. Distrust, on the other hand, is a suspicious and apprehensive attitude. But absence of trust is not equal to distrust, there are intermediate stages of relationship development (Jones, 1996). Trust and distrust are opposite notions, but are not mutually exclusive (Govier, 1992). Trust is needed when the amount of necessary knowledge is not enough (Hawley, 2014). For example, in the process of interaction with a virtual stranger we cannot know for sure how respectable and honest he or she is, or make an assumption about his or her capacity to keep confidential information or to do a favour. Therefore every time trust is a result of choice, a decision or a sequence of decisions about the openness and the optimistic expectations about the interaction (Spinosa et al., 1997). That is why some authors emphasise the presence of a certain risk in a trust-based attitude, which is an important characteristic of the phenomenon (Solomon and Flores, 2001). 
The purpose of this article is not only to describe the different definitions but present some results of our research. Mayer et al. (1995), introduced the "Proposed Model of Trust" that described the components of trust and the factors concerning the trust or and then the trustee that lead to trust.

For the economic model of relationships based on trust (Gurieva and Shmatko, 2014) we have chosen the following elements such as the subject and object of trust. Each of them has a certain amount of knowledge, understanding and experience regarding trust retaliations. In the process of interaction experience the subject and object of trust shape attitudes and expectations to the surrounding world. We will refer to the totality of these beliefs, attitudes and ideas as the Bank of Trust. In addition to the usual relations towards the outside world, we need to consider self-trust. The following picture presents the main components: The act of trust, the loss of trust, limits of trust, consequences of broken trust, Fig. 1.

In each situation with a need to choose between trust and distrust the subject establishes his or her own credit of trust to others. Sometimes we cannot know what to expect from the object of trust and it might be the case that we are willing to credit another person with a certain level of trust. Moreover, it is not only the credit of trust to the given object (person), which is shaped at this stage, but the credit of trust to a generalised image of surrounding objects. Thus, the credit of trust can be directed at the partner in interaction, as well as to the situation itself (in this situation, in the given circumstances, he or she will not let me down). The amount of credit (the level of trust at the beginning of interaction) is determined by the experience and the perception of the possibility to trust, i.e., banks of self-trust and trust to others. Besides, the subject, in order to improve their predictive capability, puts themselves at the place of the object and estimates how much they could trust themselves in such a situation, which means that they establish the credit of self-trust. Thus in the psychological field of the subject we have banks of self-trust and trust to others (linking the whole experience), credits of self-trust and trust to others (relevant to the given situation).

Johnson-George and Swap (1982) stated that «willingness to take risks may be one of the few characteristics to all trust situations». Therefore, the capacity to trust and the willingness to take risks may be the basic constituting components in every trust situation. So trust will lead to risk taking in a relationship, but the form of the risk taking depends on the situation where a subject connects to trust rating.

At this stage the general expectations are corrected by the image of the real object and the situation of interaction. The adapted level of trust forms the bank of trust in interactions with others. This is the basic level of trust of the subject to the object, the one that the object has to face in this process. In that way the subject gets the information about the attitude of the other person, so the bank of trust has an influence on the credit of selftrust and on the bank of trust to others of the object (a positive or a negative attitude from outside triggers a response). The knowledge of the level of trust of the subject shapes the object's perception of meeting the expectations. These changes are transferred to the bank of self-trust, where the whole experience relative to the object's reliability is stored.

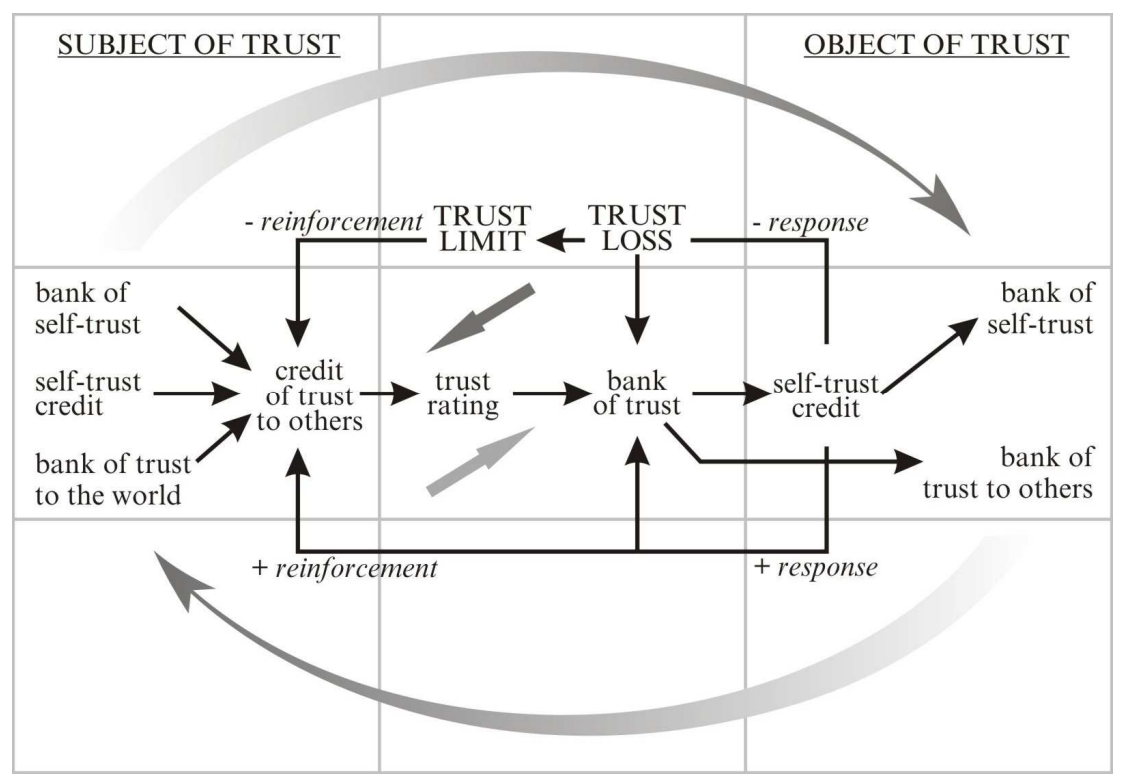

Fig. 1. The economic model of trust relationships 


\section{Methodology}

The aim of this research is to study social representations of trust among young people. The main hypothesis of the research is that these social representations are influenced by factors determining the content characteristics of trust, level and direction of trust. Thus, we have a possibility to describe steady representations of direction, conditions for trust and factors shaping social representations of trust.

\section{Participants and Overview}

The subjects of the study are 380 people: 190 men and 190 women aged between 20 and 30 (average age23.78) (Table 2).

We have designed an original questionnaire including questions that allow us to understand what expectations the respondent associate with trust, whether they consider negative or positive consequences ("What does the sensation of trust give you in your life?"), to study the connection between negative experience or its absence with self-evaluation on trust and attitude to trust ("Have you ever experienced situations in which your trust was undermined?").

The unique "Trust Situation" projective technique, developed by authors, where we asked the respondents to remember and describe a situation where they were facing a choice ('To trust or not to trust?'), is aimed at determining the significant subject and object of trust.

To determine the level of self-evaluation on trust, the respondents were asked to evaluate themselves on a scale of trustfulness. They were given the following task: "Do you consider yourself a trustful person? Please give an estimate on a scale of 1 to 10 ". The received data allows us to evaluate the subjective perception of an individual of how often he or she trusts someone and to compare these results to representations of trust and other indices.

The sentence completion method has been applied for a long time in experimental psychology. Numerous variants of the test have been developed. We based our work on the original sentence completion test designed by Sachs and Levy (1950). It includes 60 incomplete sentences which can be divided into 15 groups, each characterizing in a certain way the system of attitudes of the subject to family, to representatives of his or her own and another sex, to sexual relations, to hierarchical superiors and subordinates. Some groups of sentences are related to the subject's fears and apprehensions, to the sense of guilt, they also show the attitude to past and present, the relationships with parents and friends and the subject's own life goals.

We also used a modification of Sachs and Levy's Sentence Completion Test; some scales were removed to save respondents' time.
Table 2. The subject of the study

\begin{tabular}{llll}
\hline Sex & Men & Women & Total \\
\hline Number of respondents & 190 & 190 & 380 \\
Average age & 24.1714 & 23.3824 & 23.7826 \\
Mean average deviation & 2.8644 & 3.1624 & 3.0189 \\
\hline
\end{tabular}

\section{Procedure}

The research was conducted in several stages. The first stage was done in 2012-2013 and consisted of pilot studies aimed at designing and adapting authors' methods and establishing a plan of the core study.

In 2014-2015 the main part of the research was conducted, including surveys and diagnostic methods aimed at the study of personal, sex and age related particularities of social representations. The data was collected online, the respondents could choose the time and place that suited them best to do the survey.

The resulting data was analysed using the SPSS 20 software, factor analysis was applied and qualitative results were processed by content analysis (3 experts were involved).

\section{Measurement and Results}

To study the phenomenon of trust it was indispensable, in our opinion, to consider the object of trust. Understanding its functioning mechanisms gives us insight into the motives of decision-making on whether to trust a given object or not. What is the basis of this mechanism? What influences the choice: To trust or not to trust? What considerations does an individual take into account in making his or her choice? What criteria define trustworthiness? Responses to these questions were received via analysing incomplete sentences. For example, the sentence "I trust someone who...". See the content analysis results in Fig. 2.

Most respondents (46\%) base their decision on the cognitive component of trust functioning, i.e., knowledge about the object's actions: "Does not deceive me", "Has not discredited himself", "Justifies his point of view", "Likes and appreciates me", "Has deserved my trust", "Proved that he could be trusted". I.e., the representatives of this category in choosing between trust and distrust analyse the interaction experience they have with the object and evaluate his actions. In $13 \%$ of cases respondents described emotion and evaluation qualities of the object necessary for them to trust him: "Honest", "Sincere", "Frank", i.e., they have a certain image of an individual that can pretend to be an object of trust. Thus, $59 \%$ of the respondents have a set of demands towards an object of trust which include notions of certain behavioural characteristics and personal qualities.

But a section of the respondents (13\%) relies on the relationship status: Friends, notarized relations, family 
bonds. This category has two interesting characteristics. First, it is connected to the category of evaluation of the partner's actions and of the interaction experience, because the interaction experience is connected to the relationship status. Second, representatives of this group do not need constant analysis of the relationship. Preference to the evaluation of its status simplifies the choice of level of trust. If the individual is a friend, a partner or a family member, trust is given to him or her automatically. In this system we see an increase in automatization and a decrease in freedom of choice.

Only $9 \%$ of respondents prioritize their feelings and emotions when choosing the object of trust. For trusting an individual they have to feel faith, love towards him and to feel closeness and calm during interaction. It is worth noting that $4 \%$ of respondents said they preferred not to trust anybody and $15 \%$ could not make a decision on whether to trust or not. Overcoming the syndrome of mistrust or of different manifestations of quasi-trustful relationships (relationships that compensate for the absence of basic trust between people) is determined by a set of factors, "the most important being development of democratic bases of public life, overcoming the economic crisis, improvement of ethic and civil culture of the population and responsibility of the authorities themselves" (Skripkina, 2003).

Thus, we can say that the overwhelming majority of respondents $(81 \%)$ have certain representations of whom and how they can trust, based on personal experience, which determines the acceptable and necessary level of trust.

Let us now consider the question of who becomes an object of trust more often. We asked the respondents to describe a life situation in which they needed to make a decision: To trust or not to trust. The responses can help us to study the most significant spheres of manifestation of trust and significant objects of trust. The content analysis results divide the responses into three groups (Fig. 3).

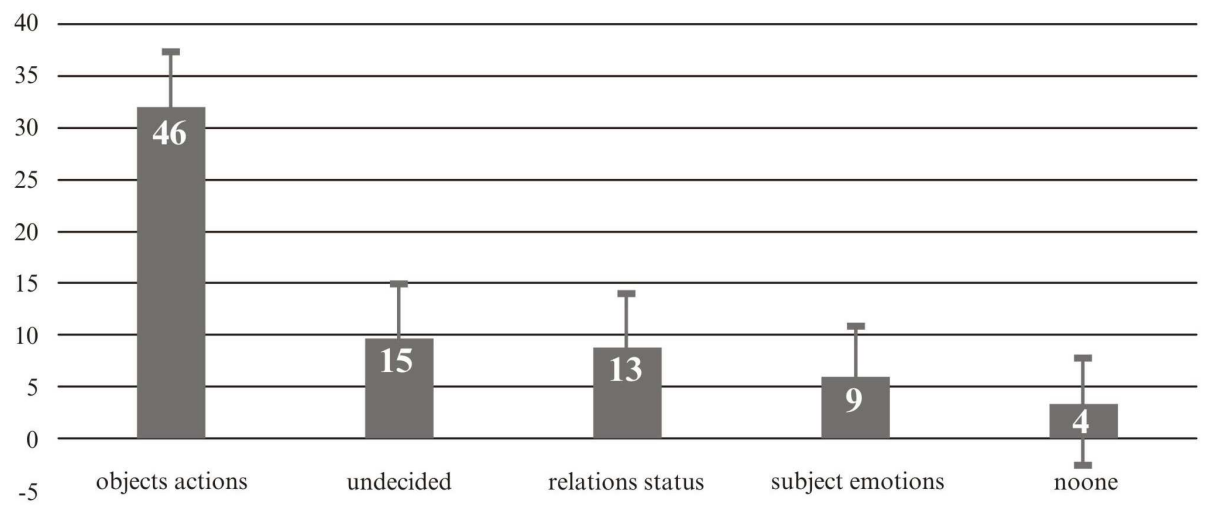

Fig. 2. Distribution of representations of the object of trust

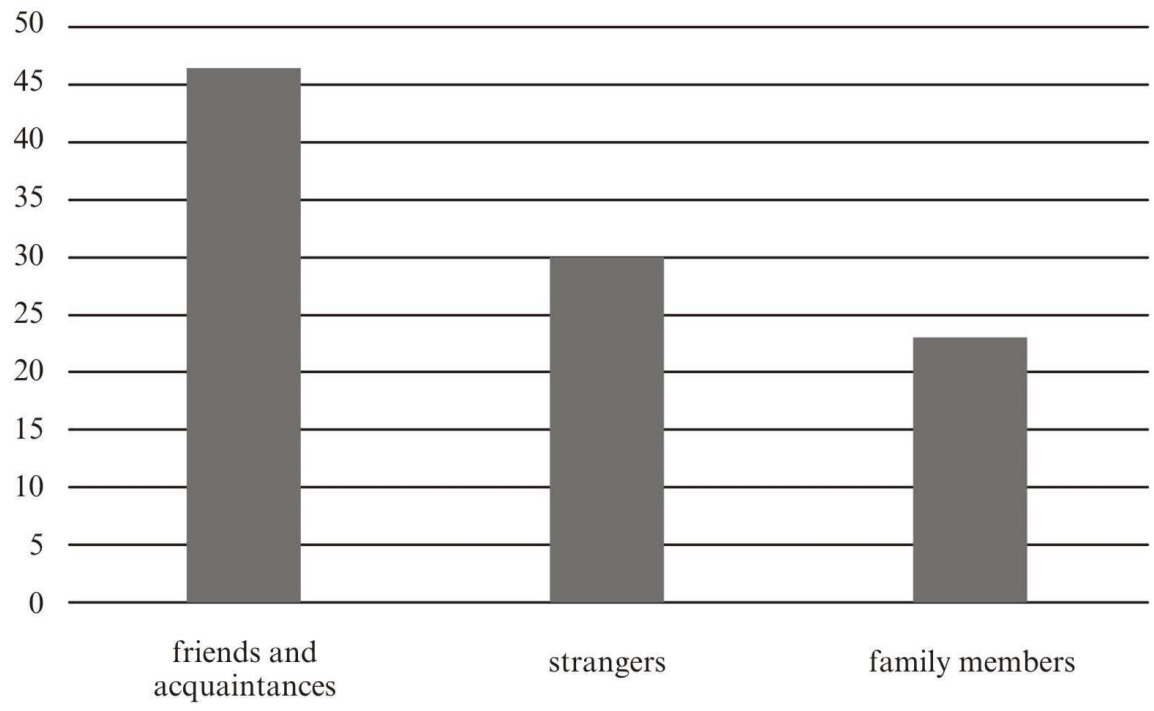

Fig. 3. Frequency of mentioning an object of trust 
Most often the respondents remembered situations of uncertainty and choice of level of trust in interaction with acquaintances, friends and colleagues (46.7\%). More rarely, they described trust in strangers and virtual strangers $(30 \%)$. About $23.3 \%$ of responses described relationships with close relations and family members (parents, children, spouses).

What are the possible reasons for such a distribution? Uncertainty surrounding questions of trust and importance of the decision are higher in relationships with friends and acquaintances than in those with strangers. We suppose it is due to the fact that the result of trust (whether it will be undermined or not) is more important in close relationships. When such trust is deceived, this can ruin a relationship that is already built, just as the hopes and images of this relationship will be ruined. When it comes to undermined trust in strangers, it only brings about losses related to the matter of trust. In such situations the subject has fewer representations of the relationship and fewer expectations about the object that can potentially be ruined.

At the same time, close family relationships are mentioned more rarely in the respondents' stories. We suggest this is due to the fact that such relationship more rarely raise the question of whether to trust or not. The subject already has more adequate knowledge of the object and a habitual level of trust is already shaped.

\section{Analysis of the Results}

The results of the "Describe a trust situation" technique help us determine the most significant matter of trust: What and about what does the respondent trust in an individual? We asked the respondents to describe a life situation in which they had to make a decision whether to trust someone or not. Content analysis results divide the responses into three groups (Fig. 4).

Most often, the respondents remembered situations in which they had to decide whether or not to trust a person after a betrayal, whether to trust his or her expressions of love, the attitude he or she shows (35\%). Here they described their concerns about possible infidelities and conflicts and also about making closer relationship ties (starting a family, beginning a relationship). About 26.7\% of stories are related to the question of trust in information given by the object: "Is he lying or telling the truth?", "Can I trust his opinion? Maybe he is mistaken..." One fifth of respondents describe situations related to risk and safety. This group includes dangerous situations where the object of trust has the possibility of saving the subject (medical intervention) and situations with potential danger from the object himself (suggestion of spending time together from a stranger). Respondents also often remembered cases when they had to decide whether to trust certain material valuables (money), whether or not to lend money, whether or not to invest their money in a project. Thus we determined major vectors of trust: Relationships, information, safety and valuables.

We studied the correlation between representations of matter and object of trust mentioned in the descriptions of situations of trust using Pearson's chi-squared test and came to the conclusion that these categories are not interconnected $(p>0.05)$. These results prove the universality of matters to all types of objects of trust.

\section{Factor Analysis of the Structure of Social Representations of Trust}

To define factors and factor weights of different variables we used factor analysis including the main components method. The number of necessary factors was determined using the Kaiser criterion and the interpretation of the defined factors was done using the rotation method. The scree plot allowed us to suggest that defining four factors would be enough for a comprehensive description of twenty-three variables standing for the evaluation of attitude to trust and other indices, criteria for trust and trustfulness self-evaluation. The factor weights matrix helped us to define the variables most closely related to each of the factors and, consequently, the importance for their interpretation which we began after the mathematical analysis (Fig. 5).

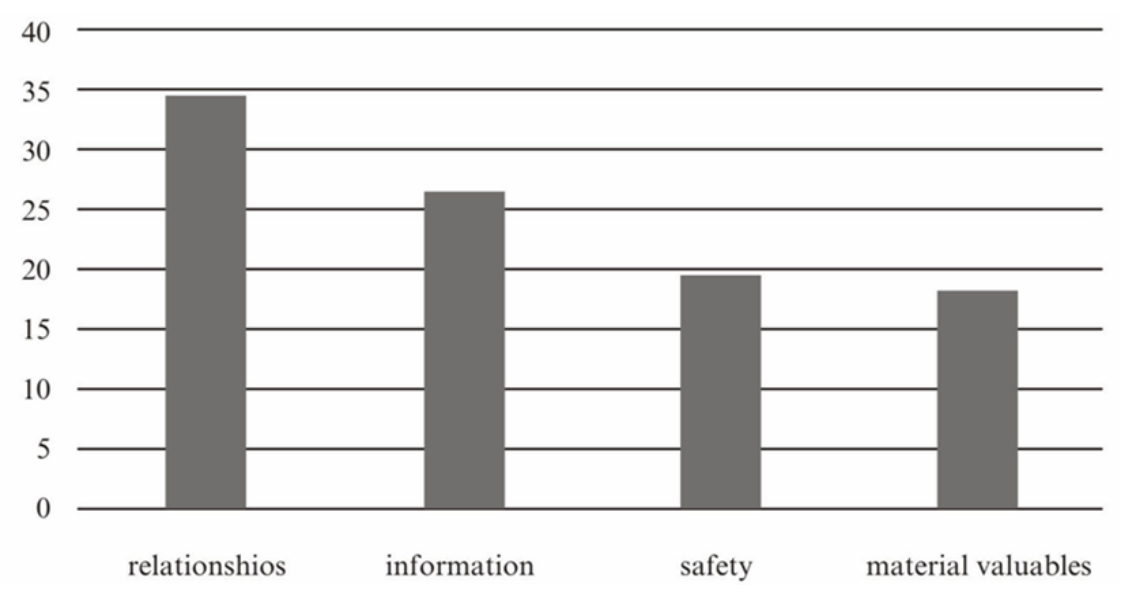

Fig. 4. Frequency of mentioning the matter of trust 


\begin{tabular}{|c|c|c|c|c|}
\hline & \multicolumn{4}{|c|}{ Component } \\
\hline & 1 & 2 & 3 & 4 \\
\hline $\begin{array}{l}\text { Reliability of the person } \\
\text { trusted the most } \\
\text { Sympathy to the person } \\
\text { trusted the most }\end{array}$ & 883 & 070 &, 156 & \\
\hline $\begin{array}{l}\text { Reasoning in the } \\
\text { relation with the person } \\
\text { trusted the most }\end{array}$ & 844 &, 150 &, 135 &,- 118 \\
\hline $\begin{array}{l}\text { Knowledge of the } \\
\text { person trusted the most }\end{array}$ &, 832 & 116 & .099 &,- 131 \\
\hline $\begin{array}{l}\text { Unity with the person } \\
\text { trusted the most }\end{array}$ & 812 & 350 & &,- 153 \\
\hline $\begin{array}{l}\text { Flaws of the person } \\
\text { who failed the trust }\end{array}$ &, 745 &, 147 &, 099 &,- 046 \\
\hline $\begin{array}{l}\text { Reasoning in the } \\
\text { relation with the person } \\
\text { who failed the trust }\end{array}$ & 689 & 230 &,- 147 & \\
\hline $\begin{array}{l}\text { Sympathy to the person } \\
\text { who failed the trust }\end{array}$ & 524 & 472 & & 295 \\
\hline $\begin{array}{l}\text { Reliability of the person } \\
\text { who failed the trust }\end{array}$ & 204 & 740 &,- 129 &,- 262 \\
\hline $\begin{array}{l}\text { Unity with the person } \\
\text { who failed the trust }\end{array}$ & 229 & ,731 & 218 &, 147 \\
\hline $\begin{array}{l}\text { Knowledge of the } \\
\text { person who failed the } \\
\text { trust }\end{array}$ & 226 &, 713 & &,- 084 \\
\hline $\begin{array}{l}\text { Attitude to the future } \\
\text { Attitude to the past }\end{array}$ & 309 & .628 & &,- 235 \\
\hline Self-attitude &, 156 &,- 152 &, 729 & \\
\hline $\begin{array}{l}\text { Attitude to missed } \\
\text { opportunities }\end{array}$ &,- 138 & 349 & 671 & 207 \\
\hline Attitude to friendship & .094 &,- 168 & .610 &, 058 \\
\hline $\begin{array}{l}\text { Flaws of the person } \\
\text { trusted the most }\end{array}$ &, 079 & 241 &, 510 &,- 188 \\
\hline $\begin{array}{l}\text { Trustfulness self- } \\
\text { evaluation }\end{array}$ & 263 & -206 & 474 & \\
\hline Attitude to family &, 432 & 327 &,- 439 &, 167 \\
\hline Attitude to guilt &,- 092 & & 429 &,- 422 \\
\hline Attitude to trust &,- 086 & 247 & 412 &, 136 \\
\hline Attitude to fear &,- 135 &,- 063 & & 690 \\
\hline Attitude to betrayal &,- 169 & &, 165 &,- 605 \\
\hline & -288 & & 196 &, 552 \\
\hline &,- 083 & -211 &, 076 & 353 \\
\hline
\end{tabular}

Fig. 5. Matrix of factor weight of the turned components

The statistical significance level when using the tenfactor model was $p=0.68$, which proves that this number of factors is enough for describing the given variables. At the interpretation stage we defined variables with the most significant weights for each factor and named the factor accordingly. Thus we defined four factors for shaping social representations of trust.

The first factor characterises the expressed level of positive attitude to a manifestation of trust and was named "Positive experience in trust situations". High levels of this factor suggest more readiness to positive perception of situations and denial of negative experience.

The first factor has the most significant factor weights in the following variables: Reliability of the person trusted the most $(r=0,883)$, sympathy to the person trusted the most $(r=0,844)$, reasoning in the relation with the person trusted the most $(r=0,832)$, knowledge of the person trusted the most $(r=0,812)$, unity with the person trusted the most $(r=0,745)$, flaws of the person trusted the most $(r=0,432)$, flaws of the person who failed the trust $(r=0,689)$, reasoning in the relation with the person who failed the trust $(r=0,524)$.

The second factor named "Negative experience in trust situations" characterises the level of negative attitude to a manifestation of trust and suggests a fixation on memories of deception in trust and a search for flaws in the individual that the person trusts. This factor has the most significant factor weights in the following variables: Reasoning in the relations with the person who failed the trust $(r=0,472)$, sympathy to the person who failed the trust $(r=0,740)$, reliability of the person who failed the trust $(r=0,731)$, unity with the person who failed the trust $(r=0,713)$, knowledge of the person who failed the trust $(r=0,628)$, knowledge of the person trusted the most $(r=0,350)$, attitude to the past $(r=$ $0,349)$, flaws of the person trusted the most $(r=0,327)$.

The third factor, "Pragmatic analysis", characterizes the level of pragmatism, of prudence in a manifestation of trust and suggests a comprehensive evaluation of knowledge, images and experiences allowing determination of the level of trust. The third factor had the most significant weights in the following variables: Attitude to the future $(r=0,729)$, self-attitude $(r=0,610)$, attitude to missed opportunities $(r=0,510)$, attitude to friendship $(r=0,474)$, attitude to the past $(r=0,671)$, flaws of the person trusted the most $(r=-439)$, attitude to family $(r=0,412)$, trustfulness self-evaluation $(r=0,429)$.

The fourth factor characterises the level of tolerance towards the possibility of betrayal, of negative attitude towards the manifestation and maintaining of trust. The fourth factor had the most significant weights in the following variables: Trustfulness self-evaluation $(\mathrm{r}=$ $0,422)$, attitude to trust $(r=-0,605)$, attitude to betrayal ( $r$ $=0,353)$, attitude to guilt $(\mathrm{r}=0,690)$, attitude to fear $(\mathrm{r}=$ $0,552)$. We named this factor "trust blindness": It causes a denial of the possibility of trust and fear of being deceived by an individual.

Let us consider the reasons behind defining the factors in more detail, taking as an example the fourth 
factor: When a person does not fear betrayal, justifying it, they reduce the significance of trust towards others: It is not important for them to trust the other person if they accept the possibility that the object may fail their expectations. People do not need to experience self-trust, if they do not suffer painful feelings of guilt for their mistakes. There is no need to have a high level of trust towards the world, if an individual has no fears or knows how to overcome them. With little need for trust the quality of trustfulness is no longer desirable and the attitude towards this phenomenon is not optimistic. Thus, intolerance of unpredictability, as well as the sense of guilt and fear is related to the feeling of necessity and importance of trust and trustfulness. Tolerance, on the contrary, to some extent substitutes the need for trustbased relations with others, oneself and the world.

To sum up the factor analysis results, we can state the following: Each group represented for the factor of attitude towards trust includes people who could be characterised as having positive experiences with manifestations of trust; having negative experiences with manifestations of trust; people with a pragmatic, rational attitude to trust; not excluding situations where tolerance of betrayal is necessary, rather than maintaining trust. Thus, trust can be a necessary component for shaping tolerant relationships, in recognizing other people's right not to be similar to us in our established system of values, beliefs, preferences and hence an established system of social representations of trust.

\section{Discussion and Limits}

In the structure of trust we can define cognitive, emotional and behavioural components. Emotional and cognitive components are correlated, including emotional evaluations of the process of trust-based interaction, common emotional background and representations of the object and the situation. Conative component is the most complicated one and is manifested in readiness to perceive the information received from the partner and further actions.

There is a certain set of images of a possible object of trust, his or her qualities and characteristics, level of acquaintance with him or her and the status of the relationship between the object and the subject. There is also a universal set of social representations of the matter of trust: People can entrust material valuables, questions connected to the relationship with the object, certain information or believe some information given by the object and trust him or her with regards to life safety. In this research we defined and described four groups of factors, which comprise the system of inner links related to trust:

- Positive experience in trust situations

- Negative experience in trust situations
- Pragmatic analysis of the situation

- "Trust blindness"

Consequently, we defined four types of individuals who have different perceptions of trust as a phenomenon, trust situations, object of trust: Emphasising positive experience, negative experience, pragmatism and analysis and denying trust.

\section{Conclusion and Future Studies}

The results of the study allow us to look at the issue of building trust-based relationships and therefore at the search for a mechanism of regulation of social behaviour as a relevant and important scientific sphere, on the one hand and on the other hand as a complex and controversial issue, lacking unanimous understanding. In the definitions of trust, in various approaches and directions there are not only differences in understanding the phenomenon of trust, but also differences in the significance of trust as a component of successful relations. The issues of correlations between trust and credulity, trust and confidence, trust and willingness to take risk remain controversial. We believe it is necessary in the future research to find more accurate ways to measure these indicators.

In the presented model of building trust-based relationships we determined the important components of a trust act, defined the actors, the possible limitations in trust, willingness and/or unwillingness to use proper resources of trust (bank of trust). However, we suppose that the model can be updated to show the role and significance of the social situation of interaction, taking into account the role of context. We also realise that the major difficulty in studying trust is the study of the context of establishing communications, in which the phenomenon of trust can either be an important and dominant component or be completely overshadowed by the context.

As it was demonstrated in the article, researchers themselves have polar views on role of trust in building and maintaining relationships. Thus, some of them do not exclude the possibility of establishing successful relationships not based on trust. Trust can result in cooperation, but is not an indispensable condition for building cooperation and communication. In our opinion, in the future this point can lead to opening new perspectives for further research on the issue of building trust-based relations. We assume that the existing representations, understanding, role and meaning of trust are based on a complex system of attitudes to the surrounding world, to others, to oneself. Our future task is to conduct a large-scale cross-cultural study taking into account all the controversial and complex issues described above and minimising the limitations we mentioned. 


\section{Acknowledgement}

We thank our unknown reviewers for their review and comments that greatly improved the manuscript.

\section{Funding Information}

This work was supported and funded by the Psychology Department of Saint Petersburg State University.

\section{Author's Contributions}

Svetlana Gurieva: Developed the conceptual idea and design of the research work.

Maria Borisova: Carried out the study, data collection of the study sample and writing the manuscript.

Olga Mikhalyuk: Provided critical research reviewing for significant intellectual content.

Victoria Dmitrieva: Provided the writing of discussion and conclusion and future direction of studying.

Veronika Odintsova: Participated in the results analysis, contributed to the drafting of the article.

Takeyasu Kawabata: Carried out the study of problem in cross cultural context, writing the intellectual research part of article.

\section{Ethics}

This article is original and contains unpublished materials. The corresponding author confirms that all of the other authors have read and approved the manuscript and there are no ethical issues involved.

\section{References}

Alexeeva, A.Y., 2007. Phenomenon of personal trust in situations of institutional loans. PhD Thesis, Novosibirsk.

Antonenko, I.V., 2006. Socio-psychological conception of trust. Moscow, Flinta, Nauka.

Bible, 1990. Books of holy scripture of the old and new testament. Moscow.

Diamond, S., 2011. Getting More: How You Can Negotiate to Succeed in Work and Life. 1st Edn., Portfolio, London, ISBN-10: 0141049944, pp: 386.

Dasgupta, P., 1988. Trust as a commodity. Basil Blackwell, New York.

Dobrokhotov, R.A., 2010. Problems of trust in the world politics. PhD Thesis, Moscow.

Dostovalov, S.G., 2013. Trust in the social world as a factor of formation of legal consciousness in adolescents. Phylology and Law.

Gambetta, D., 1988. Can we Trust in Trust? In: Trust: Making and Breaking Cooperative Relations, Gambetta, D., (Ed.), Basil Blackwell, Oxford, ISBN-10: 0631155066, pp: 213-237.
Giddens, A., 1991. Modernity and Self-identity: Self and Society in the Late Modern Age. 1st Edn., Stanford University Press, Stanford, ISBN-10: 0804719446, pp: 256.

Govier, T., 1992. Trust, distrust and feminist theory. Hypatia, 7: 16-33.

DOI: $10.1111 / \mathrm{j} .1527-2001.1992 . t b 00695 . x$

Gurieva, S.D. and M.M. Shmatko, 2014. Economic model of trust-based relations Modern psychology: Theory and practice. Proceedings of the 13 International Applied Research Conference, (ARC' 14), Moscow.

Hawley, K., 2014. Trust, distrust and commitment. Noûs, 48: 1-20. DOI: 10.1111/nous. 12000

Johnson-George, C. and W. Swap, 1982. Measurement of specific interpersonal trust: Construction and validation of a scale to assess trust in a specific other. J. Personality Social Psychol., 43: 1306-1317. DOI: 10.1037/0022-3514.43.6.1306

Jones, K., 1996. Trust as an affective attitude. Ethics, 107: 4-25.

Kapterev, P.F., A.M. Arsenyev and P.A. Lebedev, 1982. Selected works on pedagogy. USSR Academy of Pedagogical Sciences.

Kawabata, T. and K. Ohbuchi, 2014. The relation on inexpressive aggression and depression in college students-from the standpoint of the social information-processing model. Res. Reports Shokei Gakuin College, 68: 91-101.

Coleman, J.S., 2001. Social and human capital. Social Sci. Modern Times., 3: 121-139.

Kupreychenko, A.B., 2008. Psychology of trust and distrust. Russian Academy of Sciences, Institute of Psychology.

Laurens, T., O. Flanagan and A. Oksenberg Rorty, 1990. Trust, Affirmation and Moral Character: A Critique of Kantian Morality. In: Identity, Character and Morality, Flanagan, O.J. and A. Rorty (Eds.), A Bradford Book, Cambridge, ISBN-10: 0262061155, pp: 235-257.

Locke, J., 1998. Collected works in 3 volumes. Moscow.

Luhnmann, N., 1988. Familiarity, Confidence and Trust: Problems and Alternatives. In: Trust: Making and Breaking Cooperative Relations, Gambetta, D. (Ed.), B. Blackwell, Oxford, ISBN-10: 0631155066, pp: 94-107.

Mayer, R.C., J.H. Davis and F.D. Schoorman, 1995. An integrative model of organizational trust. Acad. Manage. Rev., 20: 709-734.

Parsons, T., 1998. System of modern societies. Aspekt Press, Moscow.

Porshnev, B.F., 1996. Social psychology and history. Moscow.

Romashkin, G.S., 2011. Trust in the Russian society: Economical and sociological analysis. Tyumen.

Rotter, J.B., 1967. A new scale for the measurement of interpersonal trust. J. Personality, 35: 651-665. DOI: $10.1111 / \mathrm{j} .1467-6494.1967 . t b 01454 . x$ 
Sachs, J.M. and S. Levy, 1950. The Sentence Completion Test. In: Projective Psychology: Clinical Approaches to the Total Personality, Bellak, L. (Ed.), Grove Press, New York, pp: 357-397.

Seligman, A.B., 2000. The Problem of Trust. 1st Edn., Princeton University Press, Princeton, ISBN-10: 0691050201, pp: 231.

Skripkina, T.P., 2003. Trust as a socio-psychological phenomenon: PhD Thesis, Moscow.

Solomon, R.C. and F. Flores, 2001. Building Trust: In Business, Politics, Relationships and Life. 1st Edn., Oxford University Press, Oxford, ISBN-10: 0195126858, pp: 178.

Spinosa, C., F. Flores and H. Dreyfus, 1997. Disclosing New Worlds: Entrepreneurship, Democratic Action and the Cultivation of Solidarity. 1st Edn., MIT Press, Cambridge, ISBN-10: 0262193817, pp: 222.
Stoliar, V.J., 2008. Trust as a phenomenon of socialeconomic reality. Tver.

Sztompka, P., 1999. Trust: A Sociological Theory. 1st Edn., Cambridge University Press, Cambridge, ISBN-10: 0521598508, pp: 214.

Takhanova, O.V., 2012. Institute of trust in modern economics of Russia. Ulan-Ude.

Zabolotnaya, G.M., 2003. Phenomenon of trust and its social functions. Bulletin RUDN, Sociol. Series, 1: 67-73.

Zinchenko, V.P., 1998. Psychology of trust. Philosophic Matters, 7: 76-93. 